\title{
Energy-saving behavior of households in a digital and nature-like economy as an object of research
}

\author{
Rais Burganov 1,*, Ludmlia Maimakova ${ }^{1}$, and Emina Altynbaiva ${ }^{2}$ \\ ${ }^{1}$ Kazan State Power Engineering University, Kazan, Russia \\ ${ }^{2}$ Kazan National Research Technical University named after A.N. Tupolev - KAI, Kazan, Russia
}

\begin{abstract}
The study of the behavioral aspects of households in the field of energy conservation is one of the activities of the global energy policy. From this perspective, the topic of the article is relevant. The purpose of the study is to consider the theoretical and methodological basis for studying the transformation of energy-saving behavior of a household in the context of the introduction of digital and nature-like technologies. The authors, based on the use of provisions (neoclassicism, institutionalism and Keynesianism), investigated the essence and manifestations of energy-saving behavior of a household in such conditions. For a deeper study, an analysis of organizational forms, institutional infrastructure, technical and technological relations arising in the process of energy consumption is proposed. Based on this analysis, a number of results have been obtained. The very concept of "energy" is used in a broad sense, as consisting of many of its types and used in consumption by households. The overall result of the study is the provision that the energy-saving behavior of households should be investigated in a comprehensive manner with the integration of various theoretical concepts. In the absence of such an integrated approach, the energy-saving process at the household level will be divided into different actions, including contradictory or even opposite ones, which will affect the effectiveness of the government measures taken.
\end{abstract}

\section{Introduction}

Household energy-saving behaviour has a special place in the energy policy of any country. This is due to many circumstances, including the need to search for a reserve to reduce the level of energy consumption, the country's focus on the use of hydrogen energy, clarification of the reaction of households to the use of the achievements of energy digitalization, in particular, smart measuring devices, etc. A considerable number of scientific publications $[1,2,3]$, etc. are devoted to the study of such circumstances. However, the new economic conditions in modern conditions require a revision of the state and development of trends in energy-saving behaviour of households. In particular, the introduction of digital and

\footnotetext{
* Corresponding author: burraabr@gmail.com
} 
nature-like technologies into the life of society and the economy [4]. Thus, the use of information and communication technologies (smart home, smart city) is becoming a new direction in monitoring and managing energy consumption in homes and cities. In addition, the saturation of technical means in households contributes to the transformation of their behaviour into energy consumption of any kind. According to Huawei, the number of wireless home broadband connections in the world increased by $20 \%$ in 2020 compared to 2019, to 35 million. And according to researchers, cloud-based forms of information storage in the next 10 years can consume about 11 percent of global electricity consumption. An additional contribution to energy savings is made by energy management systems - reducing the room temperature by $1^{\circ}$ leads to a reduction in heating costs by about $6 \%$. The influence of these factors on household energy consumption requires in-depth study. The purpose of the research is to consider the theoretical and methodological basis for the study of transformation of energy-saving behaviours of the household in modern conditions.

\section{Research methodology}

\subsection{Probabilistic Automata}

To achieve the goal of the study, the basic directions of economic theory were used, namely the provisions of the neoclassical direction, institutionalism, Keynesianism. As a new approach to the study of energy-saving behavior of the household, an analysis of organizational forms, institutional infrastructure, technical and technological relations arising in the process of energy consumption is proposed. In the work, the concept of "energy", which does not have a generally accepted meaning, is used in a broad sense, and not only as electricity. "Energy" has ancient Greek roots and came into the Russian language from German in the meaning of "active force".In disclosing the essence of energy-saving behavior of households, the concept of "behavior" plays a key role.As you know, behavioral economics studies the influence of social, cognitive and emotional factors on the process of making economic decisions by individuals or entire organizations, as well as the consequences of this influence on market components, for example, on prices, profits and resources [5]. The 2017 Nobel Prize winner in economics R. Thaler, based on the works of the classics of behavioral economics (primarily Kahneman and Tversky), questioned the conclusions of traditional economic theory and pointed out three psychological factors that determine decision-making by individuals: limited rationality, perception of fairness and lack of self-control [6]. One can also highlight the work of Belaïd F and Joumni H on behavioral attitudes towards energy conservation based on empirical research in France [7]. In general, the behavior of households on the energy market consists in actions emanating from their capabilities and desires to acquire an energy resource (demand for energy) for a certain period of time and under certain conditions and their willingness, as a seller, to provide this product for a certain fee (energy supply) [8].

\section{Research results and discussion of the results}

The analysis of energy-saving behavior of households can be based on different theoretical principles. So, from the point of view of neoclassical theory, that is, from the position of "market people", one can single out the desire of households to obtain financial benefits based on the economical use of energy resources. That is, the most stimulating direction in energy conservation is the benefit from energy savings, which is a market model of household behavior. After all, the less a household spends energy, the less it pays for it. At the same time, it is necessary to pay attention to the factors influencing the demand for energy. As you 
know, the demand for electricity is low elastic in price. Certain aspects of this statement are considered in a series of works $[9,10]$ However, when considering the consumption of other types of energy, the indicators of demand for them differ. Thus, the demand of households with and without centralized heating is different. And the elasticity is different here.

The lack of energy resources, as well as their cost, reveal the potential of households to generate their own energy and the possibility of its further distribution for a certain fee.

Representatives of the institutional theory can substantiate the energy-saving behavior of households with a desire to effectively use the functioning of various institutions of the digital economy. Timely payment for the use of electricity by many consumers is accepted as a norm of behavior. We can quote D. North, who believed that the economic behavior of an individual and an organization depends on legal norms and information rules (rules of the game) [11]. Also, within the framework of the institutional theory, the processes of energy consumption and energy saving can be explained within the framework of the concepts of the contract system, property rights, "principal - agent", etc. In particular, households in the energy supply sector must enter into contracts such as an energy service contract, an energy purchase contract, etc. Each type of contract and energy contract includes costs incurred before its conclusion, during the process of conclusion and after conclusion. The moral and educational model of energy consumption is related to social, cultural and legal institutions, in particular, to the institution of energy conservation. Institutions such as customs and traditions, respect for energy - heat resources should serve as effective substitutes for formal legal institutions, thereby ensuring resource savings in the national economy.

From the Keynesian perspective, household behavior is viewed as a system of relations in macroeconomic policy that can affect GNP, aggregate demand and aggregate supply. Within the framework of this theory, the share of household energy consumption in economic growth, growth in national income, etc. is determined. In the context of the digitalization of the economy, this share tends to grow.

However, the current situation with energy saving presupposes the search for new approaches to the study of problems in this area and not dwell on well-known theories.

Basically, the energy-saving behavior of households depends on solving a triad of problems that have arisen, which include problems in organizational relations (forms), institutional infrastructure and technical and technological links (Table 1).

Table 1. Approaches to the analysis of energy-saving behavior of households.

\begin{tabular}{|c|l|}
\hline $\begin{array}{c}\text { Name of approaches to energy-saving } \\
\text { behavior of households] }\end{array}$ & \multicolumn{1}{|c|}{ Contents } \\
\hline Organizational forms & $\begin{array}{l}\text { Phenomena or processes associated with the } \\
\text { organization and self-organization of the process } \\
\text { of energy conservation of any kind. }\end{array}$ \\
\hline Institutional infrastructure & $\begin{array}{l}\text { A set of formal / informal rules and regulations } \\
\text { affecting household energy consumption. }\end{array}$ \\
\hline $\begin{array}{c}\text { Technical and technological } \\
\text { connections }\end{array}$ & $\begin{array}{l}\text { The attitude of households to the use of intelligent } \\
\text { metering systems, for example, to control the } \\
\text { quality and quantity of electricity }\end{array}$ \\
\hline
\end{tabular}

In fact, the study of any phenomenon from the point of view of its organization is the starting point of the analysis

.Organizational forms include the purposeful activity of households in the formation of behavior in energy saving. Households should be organized in energy consumption and selforganize in the field of reducing energy consumption of any kind. Organizational forms include the distribution of responsibilities among members of the household, the effective placement of energy-receiving and energy-producing devices and equipment. And the selforganization of households in energy saving can be defined as the orderly activities of 
households in a targeted impact on the optimization of energy consumption of any kind in order to meet their needs while creating favorable and comfortable living conditions. Selforganization covers the organization of energy use for heating, air conditioning, hot water supply, cooking, lighting and household appliances, etc. Key elements of self-organization of households in energy saving as a system are awareness of the state of energy consumption, the possibility of influencing the energy saving process, determination of time periods. periods for tracking the progress of energy saving, comparative analysis of energy saving data by periods of consumption, coordination of family members in behavioral actions, control over payment transactions for used energy.

A special role in the self-organization of households in energy saving is played by the technical and technological aspects of self-organization, that is, the willingness to use technical and technological means, such as instrumentation, etc. in increasing the efficiency of self-organization of household activities in energy saving.

Household behavior is predetermined with their segmentation. The use of different types of energy in the sector is influenced by the level of income, the cost of energy, the possibilities of energy supply, the thermal performance of buildings, the climate, the efficiency and types of devices and equipment used, the availability of energy sources and their availability, as well as the state policy in matters of energy conservation and energy efficiency [12]. On the one hand, they increase in accordance with the increase in the population, the growth of its income and requirements for comfort. On the other hand, measures taken to improve the quality of new houses being built, energy saving, as well as an increase in the living standard of the population (allowing to buy new, more efficient appliances and spend more time outside the home) lead to a decrease in energy consumption by one household.

To obtain a comprehensive analysis of the energy-saving behavior of households, it is necessary to group them into homogeneous elements, and then draw an appropriate conclusion. The criterion for grouping (homogeneity) can be different circumstances, for example, household income, social status, living space per family, type of living building, provision of an apartment and / or house with general household energy metering devices, etc.

Table 2. Criteria for grouping households and types of their behavior (hypothetical approach).

\begin{tabular}{|c|c|}
\hline Grouping criteria & Type of behavior \\
\hline $\begin{array}{c}\text { Income: } \\
\text { High income } \\
\text { Low income }\end{array}$ & $\begin{array}{c}\text { energy-wasting } \\
\text { energy saving }\end{array}$ \\
\hline $\begin{array}{c}\text { Social status: } \\
\text { The head of the family is the leader } \\
\begin{array}{c}\text { The head of the family is the head's subordinates } \\
\text { The head of the family is non-working (pensioners, etc.) }\end{array}\end{array}$ & $\begin{array}{c}\text { Cess calculating } \\
\text { Calculating }\end{array}$ \\
\hline $\begin{array}{c}\text { Living space per head: } \\
\text { At the standard level } \\
\text { Above the standard }\end{array}$ & $\begin{array}{c}\text { Calculating } \\
\text { Less calculating }\end{array}$ \\
\hline $\begin{array}{c}\text { Residential building type } \\
\text { Class A + } \\
\text { Other classes }\end{array}$ & $\begin{array}{c}\text { Calculating } \\
\text { Less calculating }\end{array}$ \\
\hline $\begin{array}{c}\text { Provision of an apartment and / or a house } \\
\text { with general house energy metering devices: } \\
\text { Secured } \\
\text { Unsecured }\end{array}$ & $\begin{array}{c}\text { Energy saving } \\
\text { Energy waste }\end{array}$ \\
\hline
\end{tabular}


Of course, the selection of criteria for grouping households and their types of behavior are incomplete and controversial. For example, according to social status, a large number of criteria can be distinguished.

There is a known model in the form of a demand surface for an essential commodity of passive demand - in the "price-volume-income" space, when income will be a criterion for the homogeneity of the formation of groups. This model, when using different types of energy, must be converted.

As can be seen from Table 1, the behaviours of different segments of electricity consumers is different. In any society, households are classified for various reasons, including in relation to energy consumption. In particular, the so-called type of "survival" includes public sector workers, pensioners, disabled people, unemployed, migrants and is characterized by a decrease in income, which directly leads to the impossibility or difficulties in paying for housing and communal services. The next type of "real" consumption is formed within the achieved level of income for a given source, which is the salary at the main job and partially transfers from budgetary and extra-budgetary funds. This type of household behaviours, in contrast to the previous one, is solvent, but, despite this, the motive for consumption is survival. In this case, support from the state is required. It is also possible to single out the "wasteful" type of households that do not pay attention to the need for economical use of energy.

The use of formal and informal norms and rules is at the heart of the formation and development of institutional infrastructure in the behavior of households in the consumption of energy of any kind. The conditions and processes of energy saving are formalized in numerous legislative and regulatory documents at different levels. Only in Russia, at the federal level, over the past years, three state programs and three energy strategies have been created. However, the effectiveness and efficiency of these documents leaves much to be desired. In particular, many provisions are annually adjusted and supplemented, as a result of which the level of confidence in these documents decreases.

Technical and technological communications involves the use of intelligent measuring systems by households in energy consumption, for example, to control the quality and quantity of electricity. At present, energy-saving technologies are one of the key directions in the development of Russia's energy policy. A number of positive results have been obtained. So, the most effective ways to reduce the energy consumption of apartment buildings include the modernization of lighting systems and the installation of automated control units with weather regulation of heat supply systems [13].

The technological model of energy-saving behavior of households involves the use of modern energy-saving technologies. "Smart home", "smart city", "smart grids" are already becoming common concepts. Energy efficient technologies hold great promise for reducing the financial costs and environmental damage associated with energy use. For example, it is no longer a secret for anyone that LED lamps are more profitable than incandescent lamps of the old type. Technologies do not stand still, therefore there are a huge number of devices and systems for energy saving and energy efficiency. For example, dimmers that smoothly change the intensity of the lamps glow, adjusting their power; timers - switches that make sure that the light is turned on or off at exactly the specified time; fluorescent and LED lamps, which are environmentally friendly light sources. To save heat energy in the house, it is enough to install individual heating. In particular, researchers from the University of Gothenburg have found a way to turn ordinary windows into solar-powered heaters that can significantly increase the temperature of the glass, even in freezing weather. The main functional components of the invention are plasmonic nanoantennas. With the help of plasmons, nanoantennas are capable of intensely absorbing light, which then heats up the entire surface. 
The technological model of energy-saving behavior of households involves the use of modern energy-saving technologies. "Smart home", "smart city", "smart grids" are already becoming common concepts. Energy efficient technologies hold great promise for reducing the financial costs and environmental damage associated with energy use. For example, it is no longer a secret for anyone that LED lamps are more profitable than incandescent lamps of the old type. Technologies do not stand still, therefore there are a huge number of devices and systems for energy saving and energy efficiency. For example, dimmers that smoothly change the intensity of the lamps glow, adjusting their power; timers - switches that make sure that the light is turned on or off at exactly the specified time; fluorescent and LED lamps, which are environmentally friendly light sources. To save heat energy in the house, it is enough to install individual heating. In particular, researchers from the University of Gothenburg have found a way to turn ordinary windows into solar-powered heaters that can significantly increase the temperature of the glass, even in freezing weather. The main functional components of the invention are plasmonic nanoantennas. With the help of plasmons, nanoantennas are capable of intensely absorbing light, which then heats up the entire surface.

At the same time, there is an impact of widespread use of electronic products on the growth of household energy consumption. The so-called "vampire" electronics - devices and devices that spend energy, even when they are not actively used, significantly affect the level of energy saving. For example, a microwave oven consumes energy even when food is not being prepared - it keeps the digital clock running. And even when your computer is asleep, it is still using energy. Scientists at the US Department of Energy's Lawrence Berkeley National Laboratory say standby power accounts for $5-10 \%$ of household electricity consumption. If you turn off unused devices from the network (TV, VCR, stereo, charger), then this will reduce a significant amount of electricity consumption.

In the future, innovative ways of energy-saving behavior of households will be in demand by households. So, in Germany there is a so-called "passive housing". The thermos inside keeps the temperature almost constant for a long time without the need for additional heating or cold. Likewise, in a passive house, the desired constant room temperature can be maintained in all weather conditions with minimal operating costs. Unlike an "active" energy efficient home, a "passive" one does not prioritize the generation of alternative energy, but the minimization of costs. Its energy consumption is 40-90 percent less than that of a typical typical building. Such a house heats itself in winter and cools itself in summer thanks to highquality insulation.

Some households may not be connected to the national grid and may produce electricity themselves. Thermal energy generated by the human body is an invaluable resource. However, self-sustained power generation has been slow to develop due to high costs and inefficient technology. But the situation has changed in recent years. Households can not only generate energy themselves, but also supply it to the general grid. In Russia, since the end of 2019, the Federal Law "On Amendments to the Federal Law" On Electricity "in terms of the development of microgeneration" has been in effect. With the adoption of this law, consumers who have installed a micro-generation facility (for example, a solar panel), which provides a maximum power of no more than $15 \mathrm{~kW}$ to the external network, will be able to sell to guaranteeing suppliers and other energy sales companies the surplus of energy obtained from micro-generation not consumed for their own needs. Suppliers of guarantee, in turn, will be required to purchase such surpluses at the weighted average price of the wholesale market. To exercise the right to sell electricity, it is necessary to technically connect the micro-generation facility to local networks, as well as conclude a purchase and sale agreement with a supplier of last resort, in the coverage area of which the mini-station is located. 


\section{Conclusion}

Thus, the study of the process of changes in the energy-saving behavior of households should be based on the complex use of existing theoretical concepts, taking into account their mutual enrichment. In the absence of such an integrated approach, the energy saving process at the household level will be divided into different actions, including contradictory, or even opposite. This will be reflected in the effectiveness of decisions on energy conservation adopted by government agencies. The state should take certain measures to form the optimal energy-saving behavior of households, taking into account their possibilities of using digital and nature-like technologies. For example, there are such examples in France, in the USA. The Chinese government has also taken a number of measures to curb the growth of household energy consumption, such as energy efficiency labels, discounts on energy efficient appliances, and the introduction of tiered tariffs. [14]Thus, the formation and development of a nature-like economy will influence the change in the energy-saving behavior of households. The proposed directions for modeling possible scenarios of such changes make it possible to create favorable economic and institutional conditions for them.

The study was carried out with the financial support of the Russian Foundation for Basic Research within the framework of the scientific project No. 20-010-00099 A "Theoretical and methodological approaches to the development of models of energy-saving behavior of households in a nature-like economy.

\section{References}

1. H.S. Boudet, J.A. Flora, K.C. Armel, Energy Policy, 92, 444 (2016)

2. A.A. Salisu, T.O. Ayende, Energy Reviews, 54, 1470 (2015)

3. V.V. Vishnever, R.A. Burganov, I.V. Nusratullin, GCPMED 2018, 57, 1759 (2019)

4. R A Burganov, E A Dolonina and L R Urazbakhtina, IOP Conf. Ser.: Mater. Sci. Eng., 1089 (2021)

5. A.V Sycheva, E.N. Evstigneeva, Tavrichesky scientific observer, 6(23), 70 (2017)

6. R. Thaler, New behavioral economics. Why do people violate the rules of the traditional economy and how to make money on it (Eksmo, 2017)

7. F. Belaïd, H. Joumni, Energy Policy 140, 111406 (2020)

8. R.A. Burganov, L.V. Maimakova, L.R. Urazbakhtina, L.A. Golitsyna, IOP Conf. Ser.: Mater. Sci. Eng. 79(1), 012040 (2020)

9. A.A. Salisu, T.O. Ayende, Energy Reviews 54, 1470 (2015)

૧.. Koichiro, Nonlinear Electricity Pricing American Economic Review 104, 537

11. D.S. North, Spring 1(2), 73 (1993)

11. E.V Galperova, Problems of forecasting 2, 51 (2019)

10. V. Bogdanov, Energy Saving 7, 14 (2020)

11. P. Andrews-Speed P., G.Ma G., China's Energy Efficiency and Conservation. Springer Briefs in Environment, Security, Development and Peace, 31ю 